\title{
An Intact Cysteine-rich Domain is Required for Dystrophin Function
}

\author{
Roger D Bies, ** C. Thomas Caskey, $\$$ and Raymond Fenwick $*$ \\ ${ }^{*}$ Division of Cardiology, ${ }^{\ddagger}$ Institute for Molecular Genetics, and ${ }^{\S}$ Howard Hughes Medical Institute, \\ Baylor College of Medicine, Houston, Texas 77030
}

\begin{abstract}
The carboxyl terminus of dystrophin is encoded by a highly conserved, alternatively spliced region of the gene. The few rare mutations reported in this region are of interest in unraveling the function of the dystrophin molecule. An unusual case of infantile onset Duchenne muscular dystrophy (DMD) with an internal $3^{\prime}$ genomic deletion, and a membrane localized nonfunctional dystrophin protein, was used to explore the functional activity of this region. The patient's cDNA sequence showed an intragenic 1824-bp deletion precisely excising the cysteine rich and alternatively spliced COOH-terminal domains of dystrophin. The unaltered final $2.7 \mathrm{~kb}$ of the patients transcript was defined as a single exon localized to two genomic fragments, with the $5.9 \mathrm{~kb}$ HindIII fragment containing the stop codon. To understand the significance of deletions in this important region of the dystrophin gene, we mapped the order and cDNA coordinates for the $3^{\prime}$ genomic HindIII fragments encoding the cysteine rich and alternative splicing domains. This $3^{\prime}$ gene map was used to compare the clinical phenotype of the other reported $\mathrm{COOH}$-terminal deletions in the literature. Our analysis concludes that the cysteine-rich domain confers an important function for the dystrophin protein. ( J. Clin. Invest. 1992. 90:666-672.) Key words: Duchenne • Becker's • deletion • lymphocyte PCR • splicing
\end{abstract}

\section{Introduction}

Duchenne and Becker's muscular dystrophy (DMD/BMD) ${ }^{1}$ have been characterized by mutations in the gene encoding the cytoskeletal protein dystrophin (1-4). 65\% have been shown to be genomic deletions, and few have offered new information regarding dystrophin function. It has been shown that Becker's patients, allellic variants who have a milder form of the disease, often express detectable amounts of a truncated form of dystrophin because of intragenic deletions, presumably in noncritical

Address correspondence to Roger D. Bies, M.D., Institute for Molecular Genetics, Baylor College of Medicine, One Baylor Plaza, T809, Houston, TX 77030.

Received for publication 27 March 1992

1. Abbreviations used in this paper: BMD, Becker's muscular dystrophy; DMD, Duchenne muscular dystrophy; PCR, polymerase chain reaction.

J. Clin. Invest.

(c) The American Society for Clinical Investigation, Inc. 0021-9738/92/08/0666/07 $\$ 2.00$

Volume 90, August 1992, 666-672 regions of the molecule (5-8). In contrast, Duchenne patients have been characterized by very low levels or complete absence of dystrophin caused by mutations which presumably cause premature chain termination, message instability, protein degradation, or inability of the altered protein to localize to the cell membrane $(5,6,9,10)$.

Dystrophin is expressed in muscle, brain, and cardiac conduction tissue, and its function is still not known (11-13). However, clinical and histopathological evidence have shown that it prevents DMD/BMD in these tissues when it is normally expressed at the cell membrane $(5,6,11,14)$. Dystrophin is a cytoskeletal protein localized to the sarcolemma, though it appears to lack a transmembrane domain. In fact, one of the few measurable assays which correlate with disease is the presence or absence of membrane-localized dystrophin ( 5 , 11, 14). Ervasti and Campbell have reported an association between dystrophin and integral membrane glycoproteins, which may link the cytoskeleton to an extracellular molecule or matrix (15). One obvious way to begin to analyze for putative functional domains of dystrophin is to use molecular genetics to correlate phenotype with genotype. Rare mutations that disrupt either dystrophin function or its ability to bind the membrane may offer unique insight into structurally or functionally important domains of the protein. This type of analysis requires that some types of mutations have little effect on dystrophin's ability to membrane-associate or confer normal muscle function. One dramatic example is the deletion of $46 \%$ of the dystrophin molecule in the central alpha-helical rod domain, which results in only very mild muscular dystrophy (7).

The $\mathrm{COOH}$ terminus of dystrophin has been one domain that has received considerable interest as an important domain of the molecule (16). Several authors have suggested that this region may be involved in membrane association and protein function $(10,15,16)$. This assumption was based on the high degree of nucleotide and amino acid conservation at the $\mathrm{COOH}$-terminus among different species $(17,18)$ and the correlation of genomic deletions in this region with disease severity $(1,2,16)$. Unfortunately, most mutations with a severe phenotype have been shown to cause a frameshift and premature chain termination, with apparent degradation of the protein. As such, it has not been feasible to analyze the impact of specific $\mathrm{COOH}$-terminal deletions on protein function.

Only a few rare cases of dystrophin $\mathrm{COOH}-$ terminal deletions have the potential for structure/function analysis. One apparently contradictory report of patient C.M. with myopathy, glycerol kinase deficiency, and adrenal insufficiency was shown to have a distal COOH-terminal dystrophin gene deletion producing only a mild $\mathrm{BMD}$, suggesting less importance to this region of the molecule (19). An 18-mo-old patient, A.B., recently reported by Recan et al. (20) was shown to have a large 
COOH-terminal deletion beyond exon 49 and encompassing the glycerol kinase and congenital adrenal hypoplasia genes. This patient has a truncated dystrophin whose membrane association is unaffected by the deletion, again questioning the importance of the $\mathrm{COOH}$ terminus. This case was predicted by the authors to develop a mild phenotype based on current hypothesis $(5,6)$, though this could not yet be assessed because of his young age (20). These cases provide strong evidence that the $\mathrm{COOH}$ terminus is not required for membrane association, and raises important questions regarding the functional significance of the $\mathrm{COOH}$-terminal domains of dystrophin.

One case that may provide a clue to the structure and function of dystrophin's $\mathrm{COOH}$ terminus is a case previously characterized by DNA analysis and Western blot to have an intragenic 3 ' deletion encoding a defective dystrophin molecule that localizes to the sarcolemma (21). This case is particularly unusual and interesting because in contrast with the other cases, he has a severe muscular dystrophy. This unusual $\mathrm{COOH}-$ terminal mutation refocuses attention on this region, and may provide an answer to the apparent discrepancies among mutations in this region. One problem in analyzing $\mathrm{COOH}$-terminal deletions is that the 3 ' gene structure and exon boundaries have not been firmly established $(3,21)$. To allow comparison of this DMD patient's dystrophin mutation with other $\mathrm{COOH}$ terminal deletions, we clarified the genomic order in this interesting region of the gene, mapped the corresponding cDNA coordinates, and determined the location and structure of the final exon.

The region spanning our patients deletion was then cloned by nested polymerase chain reaction (PCR) amplification of cDNA obtained from transformed cultured lymphoblasts derived from the proband. Subsequent comparison with another COOH-terminal deletion patient with Becker's muscular dystrophy (19) clarifies the apparent disparity between these cases and provides evidence that an important region for dystrophin function lies in $<1 \mathrm{~kb}$ of dystrophin cDNA sequence encoding the cysteine rich domain of the dystrophin protein.

\section{Methods}

\section{Case descriptions}

Proband $(P)$. The defect in this study patient arose as a new mutation. Wheelchair bound by age 7 , the patient has severe myopathy and cognitive impairment, suggesting central nervous system disease as part of his phenotype. His initial serum creatine kinase was 40,000 U/liter, and cytogenetic analysis was unremarkable. Immunocytochemical analysis displayed dystrophin protein staining at the sarcolemma, and Southern analysis identified an intragenic $3^{\prime}$ end deletion (21).

\section{Other 3' deletion cases}

Patient 2496. Has Duchenne muscular dystrophy and an internal COOH-terminal 3' deletion of the 2.4-, 2.55-, and 1.45-kbp HindIII fragments (Fig. $2 \mathrm{~B}$ ). Immunochemistry not available.

Patient 357. Has Duchenne muscular dystrophy and an internal 3' deletion of the 6.8-kbp and 1.5-kbp HindIII fragments. Immunochemistry not available.

\section{Procedures}

Preparation of lymphoblast cDNA. Cultured lymphoblasts (22) from the proband $(\mathrm{P})$ and his mother $(\mathrm{M})$ were collected by centrifugation and rinsed in cold PBS. RNA was prepared by RNAsol extraction and isopropanol precipitation (23). The RNA was dissolved in water and precipitated in $5 \mathrm{M} \mathrm{LiCl}$ at $-20^{\circ} \mathrm{C}$ for $16 \mathrm{~h}$. The lithium was removed by dissolving in water followed by ethanol precipitation. A total of 500 ng of lymphoblast RNA was incubated in a vol of $9.5 \mu \mathrm{l}$ with $50 \mathrm{ng}$ of inverse primer $1 \mathrm{~b}$ (dystrophin cDNA bases $11,515-11,539$ ) at $65^{\circ} \mathrm{C}$ for $10 \mathrm{~min}$. This mixture was then chilled at $4^{\circ} \mathrm{C}$ for $5 \mathrm{~min}$. Reverse transcription was carried out in a total of $20 \mu \mathrm{l}$ using $4 \mu \mathrm{l} 5 \times$ reverse transcription buffer ( $250 \mathrm{mM}$ Tris- $\mathrm{HCl}$, pH 8.3 at $37^{\circ}, 40 \mathrm{mM} \mathrm{MgCl}_{2}, 150$ $\mathrm{mM} \mathrm{KCl}, 50 \mathrm{mM}$ DTT), $2.5 \mu \mathrm{l}$ of $25 \mathrm{mM}$ dNTPs, $1 \mu \mathrm{l}$ (200 U) Moloney murine leukemia virus (Bethesda Research Labs, Gaithersburg, $\mathrm{MD}$ ), and $1 \mu \mathrm{l}$ RNase inhibitor (Pharmacia Inc., Piscataway, NJ) incubated at $42^{\circ} \mathrm{C}$ for $1 \mathrm{~h}$. Reverse transcription and PCR oligonucleotide primers were synthesized 25 bases in length on an Applied Biosystems (Foster City, CA) oligonucleotide synthesizer.

$P C R$ of dystrophin transcript. The reverse transcription product was diluted to a final vol of $50 \mu \mathrm{l}$ for first round PCR amplification in a mixture containing $5 \mu \mathrm{l} 10 \times \mathrm{PCR}$ buffer $(100 \mathrm{mM}$ Tris-HCl, $\mathrm{pH} 8.3$ at $25^{\circ} \mathrm{C}, 500 \mathrm{mM} \mathrm{KCl}, 15 \mathrm{mM} \mathrm{MgCl}_{2}$ ), $500 \mathrm{ng}$ forward primer $1 \mathrm{a}$ (cDNA sequence 9,241-9,265), $450 \mathrm{ng}$ reverse primer $\mathrm{lb}$ (described above), and $5 \mathrm{U}$ Taq polymerase (Perkin Elmer Cetus) for 30 cycles of PCR $\left(94^{\circ} \mathrm{C}\right.$ denaturation $1 \mathrm{~min}, 60^{\circ} \mathrm{C}$ annealing $1 \mathrm{~min}, 72^{\circ} \mathrm{C}$ extension 5 $\mathrm{min}$ ). Second round (nested) PCR used $1 \mu \mathrm{l}$ of the first round product in a $50 \mu \mathrm{l}$ mixture for 30 cycles containing $5 \mu \mathrm{l} 5 \times$ PCR buffer, $8 \mu \mathrm{l} 2.5$ mM dNTP's, $500 \mathrm{ng}$ forward primer 2a (cDNA sequence 9,2689,292), $500 \mathrm{ng}$ reverse primer $2 \mathrm{~b}$ (cDNA sequence 11,321-11,345), and $5 \mathrm{U}$ of $\mathrm{Taq}$ polymerase under the same reaction conditions.

Sequencing. The PCR reaction product was subcloned by pretreating the reaction product with $10 \mathrm{U}$ of Klenow fragment (Pharmacia Inc.) for $30 \mathrm{~min}$ at $37^{\circ} \mathrm{C}$ and then blunt end ligation of the gel-isolated fragment into HincII digested pTZ19r (Pharmacia Inc.). Florescent sequencing of the subcloned product was performed on an Applied Biosystems 373A Automated DNA Sequencer (24).

Southern analysis. Southern blots using HindIII digested normal control, maternal, and proband DNA were performed as previously described (4). Dystrophin cDNA probes were derived from segments of the published sequence (25): probe 63-1a (cDNA bases 78799715), probe 63-1c (cDNA bases 10907-11512), probe E (cDNA bases $10,287-10,960)$. Probe $P$ is from the probands dystrophin cDNA (contains bases 9,268-9,432 and bases 11,255-11,345 with an internal deletion described in Fig. 2). Probes were labeled with ${ }^{32} \mathrm{P}$-dCTP(New England Nuclear, Boston, MA) using a random hexamer priming kit (Pharmacia Inc.).

\section{Results}

Transcript analysis. To accurately define the deletion mutation causing DMD in the proband and examine the effects of that mutation on dystrophin gene expression and function, we used reverse transcription and nested PCR of patient mRNA to obtain enough mutant cDNA for sequence analysis. Because fresh muscle biopsy tissue was not available, transformed lymphoblasts were used as a source of mRNA. Southern analysis of the deletion had indicated that the mutation eliminated at least 12 HindIII restriction fragments containing dystrophin exons, but that the two most distal fragments recognized by cDNA probes were retained (21). Using the cDNA sequence of dystrophin (25), we designed primary and secondary sets of oligonucleotide primers such that the proximal set included sequences within exon 60 , which is retained in the patient. This is the most distal exon to be firmly ordered in the series of HindIII fragments containing dystrophin cDNA sequences (3). The distal set of primer sites corresponded to sequences just 3 ' to the usual termination codon for the protein. As shown in Fig. $1 A$, nested amplification of cDNA with these primer pairs resulted in the synthesis of a DNA of about $260 \mathrm{bp}$ when the proband's cDNA was used as a template but no product was amplified from his mother's cDNA preparation. The prod- 

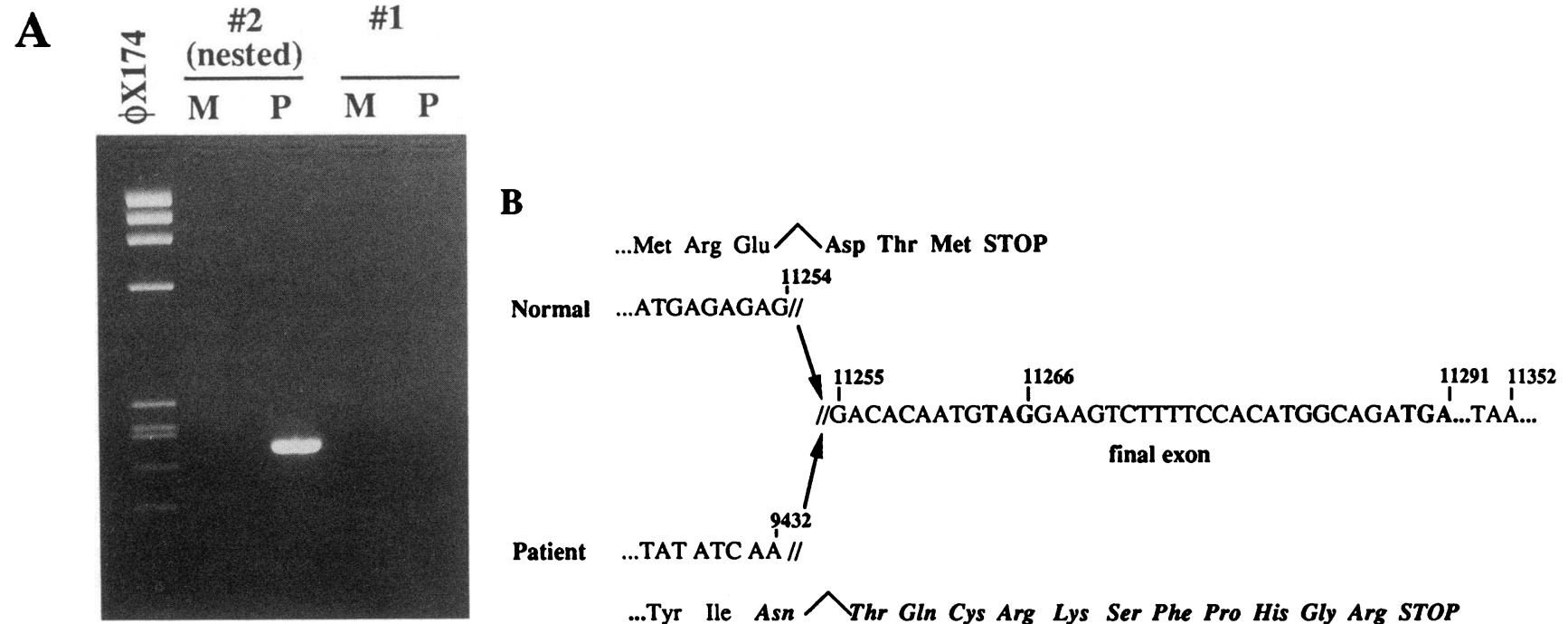

Figure 1. Nested PCR and sequence analysis of mutant transcript. $(A)$ PCR of Proband cDNA across the deletion. P, proband; M, mother; $\phi \mathrm{X} 174$, HaeIII digested $\phi \mathrm{X} 174$ DNA size marker; \#1, first round PCR with primers 1a and $1 \mathrm{~b}$ shows no visible product in the proband or the mother; \#2, second round "nested PCR" from an aliquot of reaction \#1 with primers $2 \mathrm{a}$ and $2 \mathrm{~b}$ shows a 256-bp band detected in the proband but not the mother corresponding to a 1,822 bp cDNA deletion. (This PCR product is designated Probe P, Fig. $2 A$ ). The larger predicted product at $2,078 \mathrm{bp}$ from the normal maternal transcript was not detected under these amplification conditions. (B) Sequence of Proband and normal dystrophin $3^{\prime}$ cDNA and corresponding $\mathrm{COOH}$-terminal peptide. Splicing of the final exon is indicated by arrows. The patient 5' and 3' splice sites cause a frame shift encoding for an altered $\mathrm{COOH}$-terminal peptide. The splice junctions and putative stop codons for the three different reading frames are indicated by the cDNA sequence numbers marked on the diagram. The normal and patient cDNA stop codons, and $\mathrm{COOH}$-terminal peptide sequences are in bold type. The patients altered $\mathrm{COOH}$-terminal peptide is indicated in italics. The 3 ' end of the PCR product (Fig. $2 \mathrm{~A}$ ) is at 11,345 and contains $91 \mathrm{bp}$ of sequence from the final exon.

uct predicted from the normal cDNA sequence would be 2,078 $\mathrm{bp}$, and thus should be difficult to amplify because of its length. Since the proband's mother is not a carrier of the mutation (21), it was not surprising that we could amplify neither the product obtained for the proband nor the large normal fragment from her sample.

The sequence of cloned PCR product was determined and compared to that of normal dystrophin mRNA. As illustrated in Fig. $1 B$, the mutant product was found to be missing 1,822 bp (bp 9,433-11,254). The proximal point at which the sequences diverge (bp 9,432) falls 140 bp past the end of exon 60 , the site of the proximal amplification primer and the most distal exon for which exon/intron boundaries have been published (3). The final coding exon of the dystrophin gene starts at bp 11,255 and is thus retained in the proband's DNA where its proximal splice site is used during processing of the mutant transcript. Although the final coding exon is known to be involved in alternative splicing and two of its three reading frames have been predicted to be used for translation $(18,26)$, the sequence data demonstrate that the proband's mutation causes a frame shift to the third possible reading frame. Thus, his mutation is predicted to cause the synthesis of dystrophin which lacks 608 normal amino acids and which has an unusual sequence of 12 amino acids at its carboxyl terminus. The cysteine-rich domain of dystrophin (bp 9,452-10,288) (25) is completely eliminated by the mutation as are those regions of the transcript involved in alternative splicing (bp 10,016$11,254)(18,26)$.

Genomic analysis. The genomic order of HindIII restriction fragments detected by dystrophin cDNA sequences distal to exon 60 contains several uncertainties (3). To explore the impact of rare deletions within the $\mathrm{COOH}$-terminal coding re- gion of the dystrophin gene on protein structure and function we attempted to further clarify the order of the HindIII fragments and some of their respective cDNA coordinates to compare our patient with those previously reported in the literature. The proband's chromosomal deletion was analyzed with the product amplified from his cDNA, which was used as a probe for Southern analysis of genomic DNAs from the proband, his mother and control individuals (Fig. 2 A, central panel). The results were compared to those obtained with a series of four probes that cover the distal $6,079 \mathrm{bp}$ of the normal dystrophin cDNA (see Fig. $2 B$ ). In the central panel of Fig. 2 $A$, it is seen that probe $\mathrm{P}$ identified three HindIII restriction fragments. Those of 6.6 and $2.8 \mathrm{kbp}$ correspond to fragments also identified in the left panel of Fig. $1 A$ by $63-1$ a, the probe that defines the proximal end of the patient's deletion. The 6.6and 2.8-kbp fragments are known to be distal to exon 60 , which has been localized to the $3.5-\mathrm{kb}$ fragment detected by probe 63-1a (3). Fragments of $12,2.4$ and $2.55 \mathrm{kbp}$ identified by 63-1a in normal individuals, are missing in the proband's DNA and must be located distal to the 6.6 and 2.8 fragments (Fig. 2 $A$ ). The 2.55 fragment is most distal since it is also recognized by probe $63-1 \mathrm{~b}$ (data not shown).

The 5.9-kb HindIII fragment identified by probe $P$ corresponds to the fragment also hybridized by probe $63-1 \mathrm{c}$ (Fig. 2 $A$, right panel). None of the fragments detected by probe 63-1b were found in the proband's DNA, and both fragments detected by probe $63-1 d$ were shown to be unaltered in his DNA (data not shown). Probe 63-1c defines the distal end of the deletion mutation because only one of four fragments recognized by 63-1c remains in the patient's DNA, and that fragment $(5.9 \mathrm{kbp})$ is one also recognized by $63-1 \mathrm{~d}$ (data not shown). Since probe $P$ contains the $5^{\prime}$ end of the last exon (bp 

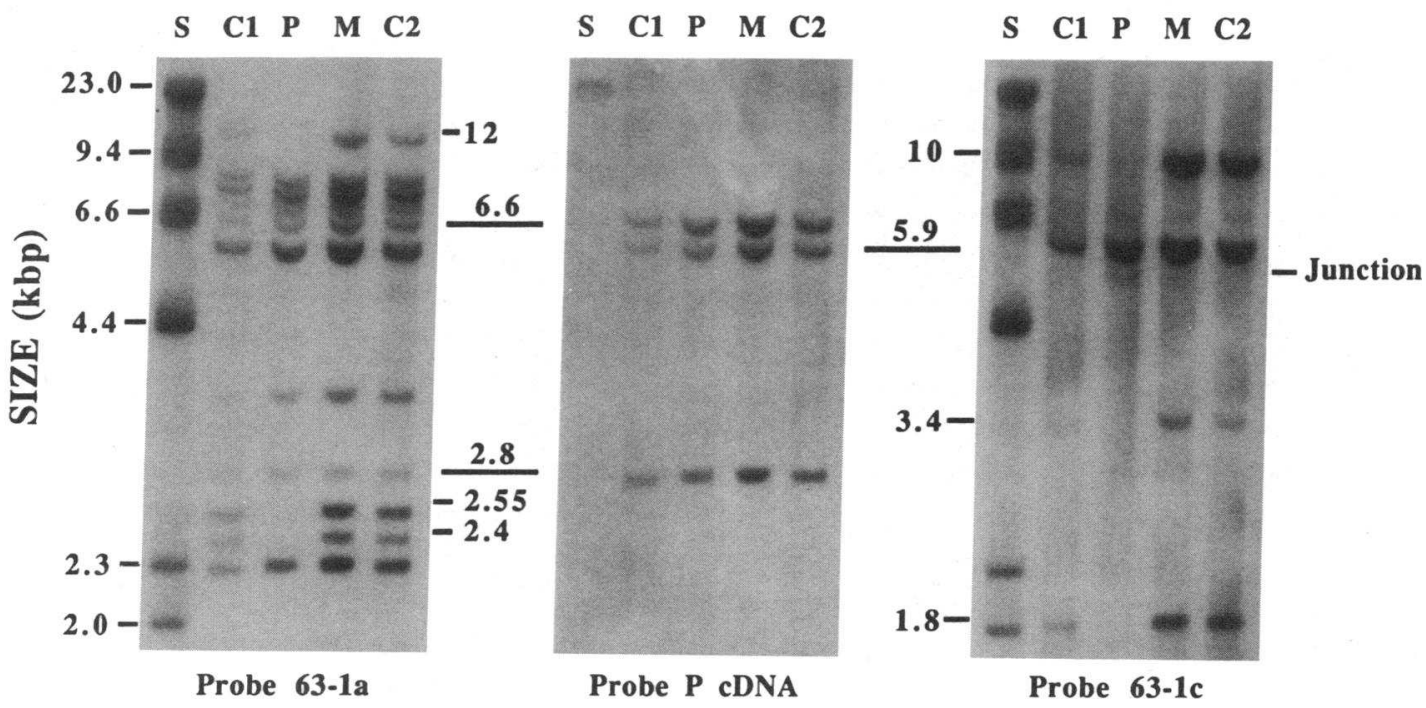

B

Genomic HindIII Fragments

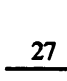
Probe E

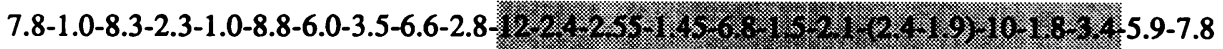

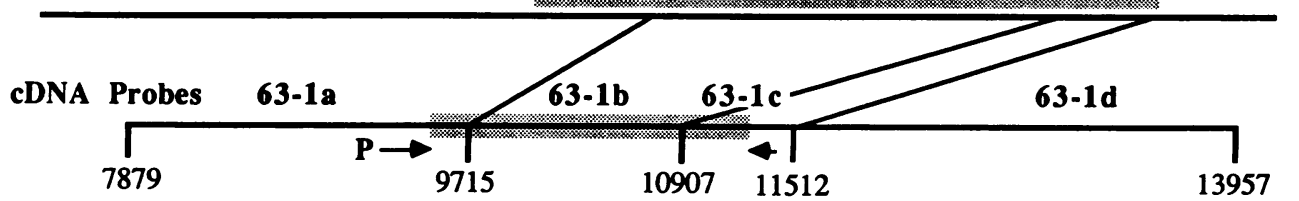

Figure 2. 3' Dystrophin gene map and Southern analysis of the proband 3' internal deletion. $(A)$ Genomic DNA HindIII digest probed with dystrophin cDNA probes. S, standard, HindIII digest of $\lambda$ DNA, P, proband; M, mother; $\mathrm{C} 1$ and $\mathrm{C} 2$, normal control DNA samples. Probe 63-1a detects the $5^{\prime}$ end of the mutation seen as deletion of the 12-kb, 2.55-kb, and 2.4-kb bands in the proband (left panel). Probe 63-1c detects the $3^{\prime}$ end of the mutation seen as deletion of the $10-\mathrm{kb}, 3.4-\mathrm{kb}$, and $1.8-\mathrm{kb}$ bands, while the $5.9-\mathrm{kb}$ band is retained in the proband (right panel). Probe $\mathrm{P}$ derived from the patients transcript (described in Fig. 1) spans the deletion, and detects the $5^{\prime}(6.6 \mathrm{~kb}$ and $2.8 \mathrm{~kb})$ and $3^{\prime}(5.9 \mathrm{~kb})$ HindIII fragments flanking the deletion (center). (B) Linear order of $3^{\prime}$ HindIII fragments detected by dystrophin cDNA probes. The cDNA base coordinates for each probe are indicated by the line diagram below. The proband deletion is indicated by fragments within the shaded area, and probe $\mathrm{P}$ is designated by the two small flanking arrows representing the location of the PCR primers used to generate the probe. The relative order of fragments listed in parentheses are not determined. The fragments deleted in C.M., a deletion with mild disease, is indicated by the line at the top of the figure which extends beyond the end of the dystrophin gene (19). The HindIII fragments deleted in patients 27,2496 , and 128.3, and those detected by cDNA probe $\mathrm{E}$ are similarly designated as a line over the respective fragments, thus establishing the fragment order represented here.

11,255 ) and the $3^{\prime}$ end of probe $P$ (bp 11,345) falls between the termination codons used in normal dystrophin transcripts ( $b p$ 11,266 and 11,352), the 5.9-kbp fragment must contain the $5^{\prime}$ end of the final exon as well as the termination codons. The normal dystrophin cDNA transcript contains a single HindIII site at bp 12,976 between the stop codons and the poly A tract at bp 13,973 (15), suggesting that the 5.9- and 7.8-kbp fragments detected by probe $63-1 \mathrm{~d}$ are contiguous. Thus, the final exon of the dystrophin gene must be $2.7 \mathrm{kbp}$ in length and is located in the distal $1.7 \mathrm{kbp}$ of the $5.9-\mathrm{kbp}$ fragment and the proximal $1 \mathrm{kbp}$ of the 7.8-kbp fragment.

The penultimate exon of dystrophin is $32 \mathrm{bp}$ in length ( 18 , 26), and was not found in the proband's transcript (Fig. 1 B). However, probe 63-1c did detect a fragment unique to the proband's DNA and slightly smaller than the 5.9-kb fragment (Fig. $2 \mathrm{~A}$, right panel) which could represent a junction fragment containing the penultimate exon. If the penultimate exon is retained, the proband's mutation must alter mRNA splicing such that the exon is removed from the transcript. It should also be noted that the 3.4-kbp HindIII fragment detected by probe 63-1c was not detected in the proband's DNA. This fragment is not detected by all investigators but the current studies demonstrate that it is part of the dystrophin gene. Since the signal for the 3.4-kbp fragment is normally weak and the penultimate exon is but $32 \mathrm{bp}$ in length, the penultimate exon is most likely found in the 3.4-kbp fragment.

Map assignments. Although the HindIII fragments identified by cDNA probes distal to exon 60 have been described (3), the genomic ordering of those fragments has been difficult due to the low frequency at which deletion mutations have been identified in this portion of the dystrophin gene. From our own data and that reported by others, we have established the order shown in Fig. $2 B$. The relative order of the 6.6 and 2.8 fragments between exon 60 and our proband's deletion is established by patient 27 reported by Roberts et al. (27) who has a deletion of the 2.8- and 12-kbp fragments. The position of the 12-kbp fragment is established by the deletion breakpoint in our proband. Our sequence data show that the $12-\mathrm{kbp}$ frag- 
ment contains the $5^{\prime}$ end of the cysteine-rich coding region. Another patient we have studied, number 2496, has a deletion which affects the 2.4 fragment detected by probe $63-1 \mathrm{a}$, the 2.55 detected by both 63-1a and $\mathrm{b}$, and the 1.45 detected by 63-1b (Fig. 2 B). Patient 128.3, described by Den Dunnen et al. (3), has an overlapping deletion of the $1.45-\mathrm{kbp}$ fragment mentioned above, and is also deleted for the 6.8 and 1.5 fragments detected by $63-1 \mathrm{~b}$ (Fig. $2 \mathrm{~B}$ ). This data compliments patient 357 , who we have studied (not shown) and who lacks the latter two (6.8 and 1.5) fragments and confirms this order. We used a cDNA probe $\mathrm{E}$, which places the $1.5-\mathrm{kbp}$ fragment distal to the $6.8 \mathrm{kbp}$ fragment (Fig. $2 \mathrm{~B}$ ), and also localizes cDNA bp 10,288 (the $3^{\prime}$ cDNA coordinate of the cysteine rich region) to this fragment. The cysteine rich region is thus contained within the 12-, 2.4-, 2.55-, 1.45-, 6.8-, and 1.5-kbp HindIII genomic fragments. With the available data there are still a few remaining uncertainties regarding the order of genomic HindIII fragments detected with dystrophin cDNA within the alternatively spliced region of the gene (Figs. $2 B$ and $3 B$ ).

\section{Discussion}

The $\mathrm{COOH}$-terminal domains of the dystrophin protein contain the sequences of the molecule most highly conserved among species $(17,18)$. This conservation has lead to speculation that this region of dystrophin is involved in interactions with other molecules that mediate attachment of dystrophin to the cytoplasmic surface of the cell membrane $(15,28)$. Because dystrophin is believed to be a cytoskeletal protein, membrane association has been considered synonymous with function and predictive of disease phenotype $(5,11,14,16)$. Recent case reports have questioned this hypotheses by demonstrating dystrophin immunostaining at the sarcolemma in patients with $\mathrm{COOH}$-terminal dystrophin gene deletions demonstrated by Southern blot analysis $(20,21)$. While the $\mathrm{COOH}$-terminal peptide sequences in these cases had not been determined, it was proposed that membrane association occurs in other regions of the dystrophin molecule. So what then is the significance of dystrophin's $\mathrm{COOH}$ terminus? In the first of these reported cases (21), the patient is old enough to allow evaluation of the effect of this rare mutation on disease phenotype. $\mathrm{He}$ has severe Duchenne muscular dystrophy suggesting a deletion of an important domain of the dystrophin protein, which does not interfere with membrane binding but completely disrupts protein function. This unusual mutation supports the concept that interspecies sequence conservation in this region is biologically significant $(17,18)$.

Recent studies have shown that genomic mutations, even when accurately defined, cannot always predict the posttranscriptionally modified mRNA sequence $(9,29)$. Transcript sequence analysis in these studies has shown that the use of alternate splicing events could produce a coding sequence that cannot be predicted by genomic DNA analysis. Such data illustrate the importance of analyzing gene mutations at the level of transcriptional sequence to avoid erroneous assignment of the mutation boundaries based on genomic DNA and antibody data. This was the major limitation in the first description of the patient analyzed in this study (21).

To fully define the biochemical defect in this patient, the mutant dystrophin transcript was analyzed from lymphoblast RNA. This appears to be a reliable method for assaying transcripts normally expressed in muscle tissue without requiring

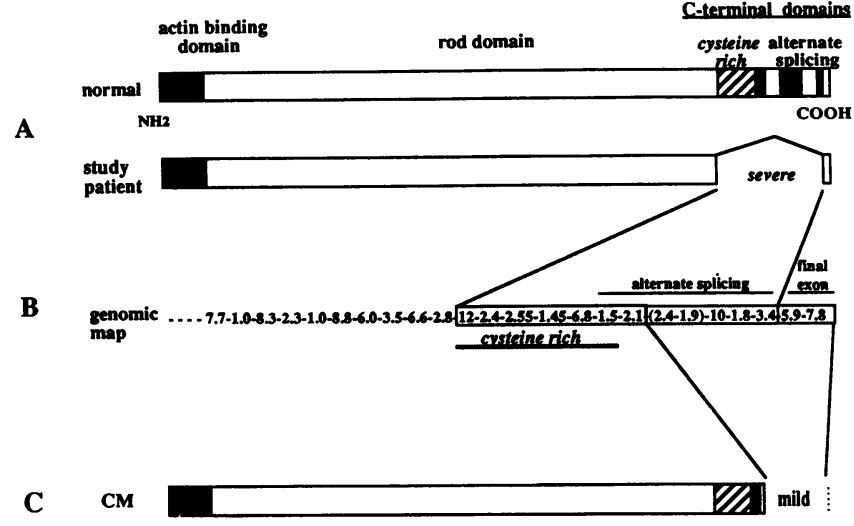

Figure 3. Schematic diagram of the functional domains of the dystrophin gene and protein and the clinical effects of two different COOH-terminal deletions. $(A)$ Normal dystrophin and the patients' mutant protein are illustrated by the relative position of putative functional domains of the protein (25). The actin binding domain (black area) is analogous to the amino terminus of $\alpha$-actinin and is thought to bind actin filaments. The rod domain (central white area) is a large structural central triple helical domain which resembles analogous domains in both $\alpha$-actinin and the cytoskeletal protein spectrin. A portion of the cysteine-rich region (cross-hatched area) is analogous to a similar domain in the carboxyl terminus of $\alpha$-actinin. The alternatively spliced domain is a region unique to dystrophin, which undergoes sequence modifications in separate tissues via alternative splicing of the mRNA $(18,26)$. The patient in this study is represented below the normal and makes a dystrophin protein deleted for the cysteine-rich and alternatively spliced domains. The deleted sequences and resultant severe DMD phenotype are indicated in the diagram. ( $B$ ) The final $253^{\prime}$ genomic HindIII fragments for the dystrophin gene are represented. The patients deletion which appears to confer severe disease is compared to the deleted segment in the very mild phenotype $3^{\prime}$ deletion C.M. case, see Fig. $3 C$. The location of the fragments containing exons which encode the cysteine rich domain are indicated by a line below the fragments. The fragments containing the final exon as well as the alternatively spliced exons are designated in a similar manner. $(C)$ C.M. represents a mild case of $\mathrm{BMD}$ with a $\mathrm{COOH}$-terminal deletion. The extent of his deletion is based on published genomic data (19), and the boundaries for the $\mathrm{COOH}$-terminal domains assigned in this study. C.M. retains the cysteine-rich domain.

an invasive biopsy procedure $(9,27,30)$. Sequence analysis of a PCR product derived from the patient's transcript spanning the patient's mutation showed a deletion of the entire cysteinerich domain and all the 3 ' alternatively spliced exons. The result is a severe disease phenotype, despite dystrophin being localized to the sarcolemma. The presence of the final exon and $3^{\prime}$ untranslated region in the proband's transcript may be important for the unusual finding that this patient translates relatively normal amounts of dystrophin (21).

Southern blot analysis of our patient showed an internal deletion of 13 HindIII fragments of the dystrophin gene while preserving the last two HindIII fragments. We have shown that these last two fragments contain the final exon for dystrophin, a large $2.7-\mathrm{kb}$ exon divided by a single restriction site found in the cDNA transcript. The reading frame for this exon starts with the first base of a codon triplet in the 5.9-kb fragment and normally encodes for only three amino acids, while the 7.8-kbp fragment contains only $3^{\prime}$ untranslated sequence (Fig. $2 \mathrm{~B}$ ). The 32-bp pentultimate exon is likely contained in the 3.4-kb 
HindIII fragment and starts with the second base of a codon triplet (18). Further studies will be required to firmly establish the genomic address for all the exons in this region, which include five alternatively spliced exons for which the cDNA splice junctions and reading frame are now known $(18,26)$.

It has been demonstrated that very large in-frame deletions in the structural "rod" domain of dystrophin can be well tolerated and show little effect on protein stability, membrane binding, or protein function as demonstrated by cases where such patients exhibit only a very mild Becker's phenotype $(7,8)$. Unfortunately, the structure/function analysis of the $\mathrm{COOH}$ terminal cysteine-rich and alternatively spliced domains of dystrophin has been limited by the relative paucity of patients with mutations in this region, and the lack of other objective assays for dystrophin function. Furthermore, predictions of protein sequence and stability by studying the effect of a mutation by reading frame ( 31 ) has been hampered by incomplete information regarding the order of genomic fragments detected by dystrophin cDNA's and the exon structure of this important region of the gene (3). We approached this problem by combining our own analysis of this region with other available data to determine the map position and transcriptional coordinates for the genomic HindIII fragments in this region of the gene.

Fig. 3 is a summary of the mutant dystrophin protein compared to hypothetical structure/function domains of the normal molecule. We have compared this deletion mutation with the genomic deletion described in patient C.M. (with mild muscular dystrophy [19]). C.M. retains the full sequence encoding for the cysteine-rich domain and sequences downstream from base 10,288 , located on the $1.5-\mathrm{kb}$ and $2.1-\mathrm{kb}$ HindIII fragments. He therefore retains the alternatively spliced domain between bases 10,016 and 10,182, which causes a frame shift that could potentially encode for a truncated isoform of dystrophin believed to be normally expressed in smooth muscle from the aorta (26). This isoform may account for the mild phenotype in this patient, though immunostaining has not yet been reported in C.M. Interestingly, comparing the C.M. deletion phenotype to the case presented here would impart a less critical importance to the distal $\mathrm{COOH}$ terminus of dystrophin (Fig. 3). The patient A.B. described by Recan et al. (20) has a multigene deletion that also includes the entire cysteine-rich and alternatively spliced domains of dystrophin. Based on our model, we would be very surprised if this patient did not exhibit a severe muscular dystrophy, despite the presence of significant amounts of membrane-localized dystrophin. Both of these patients point out the limitations of our current biochemical classification of DMD and BMD by antibody detection of protein. Comparisons between $\mathrm{COOH}$-terminal deletions (1921 ) and the central "rod domain" deletion cases $(7,8)$ supports the modified model put forth by Recan et al. (20) that a primary site for dystrophin membrane attachment may be the amino terminal actin binding domain of protein. However, this does not exclude the possibility that other important molecular associations exist within the conserved domains at the $\mathrm{COOH}$ terminus.

The mutation analysis presented in this study clarifies the $3^{\prime}$ dystrophin gene structure, and focuses attention on the cysteine-rich domain as a candidate for further studies on the molecular basis for dystrophin function. One limitation to the study of site specific mutations in the intact animal is the potential for modulation of disease severity via expression of other related molecules. Alternatively, changes in protein fold- ing may account for dysfunction unrelated to the region deleted or mutated. However, no other domain of dystrophin has consistently shown a correlation with severe disease phenotype and to date there are no exceptions to the rule that loss of cysteine rich peptide sequence causes severe muscular dystrophy. This region contains 15 cysteines in 280 amino acids, compared with the preceding 880 amino acids completely devoid of cysteines (25). It also contains an aligned 142 amino acid stretch with $24 \%$ identical matches to the $\mathrm{COOH}$ terminus of $\alpha$-actinin. The homologous region of $\alpha$-actinin includes two helix-loop-helix putative calcium binding sequences similar to the EF hand motif found in calmodulin $(25,32,33)$. Biochemical studies that show increased calcium channel leak activity and elevated intracellular calcium levels in dystrophic muscle $(34,35)$ suggest a potential role for dystrophin in normal intracellular calcium metabolism. It is unclear whether dystrophin has a direct effect on calcium flux or if these findings are related to other biochemical derangements in complexes which may normally interact with dystrophin. A direct biochemical assay remains to be developed to test the potential efficacy of recombinant dystrophin molecules which bind the cell membrane $(36,37)$, and their ability to restore normal function to dystrophic muscle. The relatively well defined cysteine rich region of dystrophin appears to offer some promise as a potential target domain to approach this goal.

\section{Acknowledgments}

Special thanks to Dr. James Lupski for providing transformed lymphoblasts from the proband.

Supported in part by the American Heart Association/Bugher Foundation center for Molecular Biology (86-2216), the Muscular Dystrophy Association, and the Howard Hughes Medical Institute (C. Thomas Caskey).

\section{References}

1. Koenig, M., A. H. Beggs, M. Moyer, S. Scherpf, K. Heindrichs, T. Bettecken, G. Meng, C. R. Muller, M. Lindlof, H. Kaariainen, et al. 1989. The molecular basis for Duchenne versus Becker muscular dystrophy: correlation of severity with type of deletion. Am. J. Hum. Genet. 45:498-506.

2. Darras, B. T., and U. Francke. 1988. Myopathy in complex glycerol kinase deficiency patients is due to $3^{\prime}$ deletions of the dystrophin gene. Am. J. Hum. Genet. 43:126-130.

3. Den Dunnen, J. T., P. M. Grootscholten, E. Bakker, L. A. J. Blonden, H. B. Ginjaar, M. C. Wapenaar, H. M. B. van Passen, C. van Broekhoven, P. L. Pearson, and G. J. B. van Ommen. 1991. Topography of the Duchenne muscular dystrophy (DMD) gene: FIGE and cDNA analysis of 194 cases reveals 115 deletions and 13 duplications. Am. J. Hum. Genet. 45:835-847.

4. Baumbach, L. L., J. S. Chamberlain, P. A. Ward, N. J. Farwell, and C. T. Caskey. 1989. Molecular and clinical correlations of deletions leading to Duchenne and Becker muscular dystrophies. Neurology. 39:465-474.

5. Hoffman, E. P., K. H. Fischbeck, R. H. Brown, M. Johnson, R. Medori, J. D. Loike, J. B. Harris, R. Waterston, M. Brooke, L. Specht, et al. 1988. Characterization of dystrophin in muscle biopsy specimens from patients with Duchenne's or Becker's muscular dystrophy. N. Engl. J. Med. 318:1363-1368.

6. Hoffman, E. P., L. M. Kunkel, C. Angelini, A. Clark, M. Johnson, and J. B. Harris. 1989. Improved diagnosis of Becker muscular dystrophy via dystrophin testing. Neurology. 39:1011-1017.

7. England, S. B., L. V. B. Nicholson, M. A. Johnson, S. M. Forrest, D. R. Love, E. Zubrzycka-Gaarn, D. E. Bulman, J. B. Harris, and K. E. Davies. 1990. Very mild muscular dystrophy associated with the deletion of $46 \%$ of dystrophin. Nature (Lond.). 343:180-182.

8. Gospe, S. J., R. Lazaro, N. Lava, B. Grootscholten, M. Scott, and K. Fischbeck. 1989. Familial X-linked myalgia and cramps: a non-progressive myopathy associated with a deletion in the dystrophin gene. Neurology. 39:1277-1280.

9. Chelly, J., H. Gilgenkrantz, M. Lambert, G. Hamard, P. Chafey, D. Recan, P. Katz, A. de la Chapelle, M. Koenig, L. B. Ginjaar, et al. 1990. Effect of dystrophin gene deletions on mRNA levels and processing in Duchenne and Becker muscular dystrophies. Cell. 63:1239-1248.

10. Ginjaar, I. B., E. Bakker, J. T. Den Dunnen, M. M. B. Van Pasassen, 
J. G. B. Van Ommen, E. E. Zubrzycka-Gaarn, M. D. Uloosterman, A. Wessels, and A. F. M. Moorman. 1989. Immunological study of dystrophin in Duchenne fetus. Lancet. ii:1212-1213.

11. Arahata, K., S. Ishiura, T., Ishiguro, T. Tsukahara, Y. Suhara, C. Eguchi, T. Ishihara, I. Nonaka, E. Ozawa, and H. Sugita. 1988. Immunostaining of skeletal and cardiac muscle surface membrane antibody against Duchenne muscular dystrophy peptide. Nature (Lond.). 333:861-863.

12. Livdov, H. G. W., T. J. Byers, S. C. Walkins, and L. M. Kunkle. 1990 Localization of dystrophin to postsynaptic regions of central nervous system neurons. Nature (Lond.). 348:725-728.

13. Bies, R. D., D. Friedman, R. Roberts, M. B. Perryman, and C. T. Caskey. 1992. Expression and localization of dystrophin in human cardiac purkinje fibers. Circulation. 86:147-153.

14. Bonilla, E., C. E. Samitt, A. F. Miranda, A. P. Hayes, G. Salviati, S. Dimauro, L. M. Kunkel, E. P. Hoffman, and L. P. Rowland. 1988. Duchenne muscular dystrophy: deficiency of dystrophin at the muscle cell surface. Cell. 54:447-452.

15. Ervasti, J. M., and K. P. Campbell. 1991. Membrane organization of the dystrophin-glycoprotein complex. Cell. 66:1121-1131.

16. Arahata, K., A. H. Beggs, H. Honda, et al. 1991. Preservation of the C-terminus of dystrophin molecule in the skeletal muscle from Becker muscular dystrophy. J. Neurol. Sci. 101:148-156.

17. LeMaire, C., R. Heilig, and J. L. Mandel. 1988. The chicken dystrophin cDNA: striking conservation of the C-terminal coding and $3^{\prime}$ untranslated regions between man and chicken. EMBO (Eur. Mol. Biol. Organ.) J. 7:4157-4162.

18. Bies, R. D., S. Phelps, M. D. Cortez, R. Roberts, C. T. Caskey, and J. R. Chamberlain. 1992. Human and murine dystrophin mRNA's are differentially expressed during skeletal muscle, heart, and brain development. Nucleic Acids Res. 20:1725-1731.

19. McCabe, E. R. B., J. Towbin, J. Chamberlain, L. Baumbach, J. Witkowski, G. J. B. van Ommen, M. Koenig, L. M. Kunkel, and W. K. Seltzer. 1989. Complementary DNA Probes for the Duchenne muscular dystrophy locus demonstrate a previously undetectable deletion in a patient with dystrophic myopathy, glycerol kinase deficiency, and congenital adrenal hypoplasia. J. Clin. Invest. 83:95-99.

20. Recan, D., P. Chafey, F. Leturcq, J. P. Hugnot, N. Vincent, F. Tome, H. Collin, D. Simon, P. Czernichow, L. V. B. Nickolson, et al. 1992. Are cysteinerich and $\mathrm{COOH}$-terminal domains of dystrophin critical for sarcolemmal localization? J. Clin. Invest. 89:712-716.

21. Hoffman, E. P., C. A. Garcia, J. S. Chamberlain, C. Angelini, J. R. Lupski, and R. Fenwick. 1991. Is the carboxy-terminus of dystrophin required for membrane association? A novel severe case of Duchenne muscular dystrophy. Annals of Neurology. 30:605-610.

22. Anderson, M. A., and J. F. Gusella. 1984. The use of cyclosporin A in establishing Epstein-Barr virus transformed human lymphoblastoid cell lines. In Vitro (Rockville). 20:856-858.
23. Chomczynski, P., and N. Sacchi. 1987. Single-step method of isolation by acid guanidinium thiocyanate-phenol-chloroform extraction. Anal. Biochem. 162:156-159.

24. Smith, L. M., J. S. Sanderts, R. J. Kaiser, P. Hughes, C. Dodd, C. R. Connell, C. Heiner, S. B. H. Kent, and L. E. Hood. 1986. Fluorescence detection in automated DNA sequence analysis. Nature (Lond.). 321:674-679.

25. Koenig, M., A. P. Monaco, and L. M. Kunkel. 1988. The complete sequence of dystrophin predicts a rod shaped cytoskeletal protein. Cell. 53:219288.

26. Feener, C. A., M. Koenig, and L. M. Kunkel. 1989. Alternative splicing of human dystrophin mRNA generates isoforms at the carboxy terminus. Nature (Lond.). 338:509-511.

27. Roberts, R. G., T. F. M. Barby, E. Manners, M. Babrow, and D. R. Bently. 1991. Direct detection of dystrophin gene rearrangements by analysis of dystrophin mRNA in peripheral blood lymphocytes. Am. J. Hum. Genet. 49:298-310.

28. Wessels, A., I. B. Ginjaar, A. F. M. Moorman, and J. G. B. Van Ommen. 1991. Different localization of dystrophin in developing and adult human skeletal muscle. Muscle and Nerve. 14:1-7.

29. Matsuo, M., T. Masumura, H. Nishio, T. Nakajima, Y. Kitoh, T. Takumi, J. Koga, and H. Nakamura. 1991. Exon skipping during splicing of dystrophin mRNA precursor due to an intraexon deletion in the dystrophin gene of $\mathrm{Du}$ chenne muscular dystrophy kobe. J. Clin. Invest. 87:2127-2131.

30. Roberts, R. G., D. R. Bentley, T. F. M. Barby, E. Manners, and M. Bobrow. 1990. Direct diagnosis of carriers of Duchenne and Becker muscular dystrophy by amplification of lymphocyte RNA. Lancet (N. Am. Ed.). 336:1523-1526.

31. Monaco, A., C. Bertelson, S. H. M. Liechti-Gallari, and L. M. Kunkle. 1988. An explanation for the phenotypic differences between patients bearing partial deletions of the DMD locus. Genomics. 2:90-95.

32. Byers, T. J., A. Husain-Chishti, R. R. Dubreuil, D. Branton, and L. S. B. Goldstein. 1989. Sequence similarity of the amino-terminal domain of drosophila beta-spectrin to alpha-actinin and dystrophin. Cell. 109:1633-1641.

33. Baron, M. D., M. D. Davison, P. Jones, and D. R. Critchley. 1987. The sequence of chick alpha-actinin reveals homologies to spectrin and calmodulin. J. Biol. Chem. 262:17623-17629.

34. Fong, P., P. R. Turner, W. F. Denetclaw, and R. A. Steinhardt. 1990. Increased activity of calcium leak channels in myotubes of Duchenne human and mdx mouse origin. Science (Wash. DC). 250:673-676.

35. Franco, A., and J. B. Langsman. 1990. Calcium entry through stretch-inactivated ion channels in mdx myotubes. Nature (Lond.). 344:670-673.

36. Lee, C. C., J. A. Pearlman, J. S. Chamberlain, and C. T. Caskey. 1991. Expression of Recombinant dystrophin and its localization to the cell membrane. Nature (Lond.). 349:334-336.

37. Acsadi, G., G. Dickson, D. R. Love, A. Jani, F. S. Walsh, A. Gurusinghe, J. A. Wolff, and K. E. Davies. 1991. Human dystrophin expression in mdx mice after intramuscular injection of DNA constructs. Nature (Lond.). 352:815-818. 